\title{
The Effect of Air Pollutants and Socioeconomic Status on Asthma in Texas
}

\author{
Faye Anderson', George L. Delclos' ${ }^{2}$, D. C. Rao $^{3}$ \\ ${ }^{1}$ Independent Scholar, Houston, Texas, USA \\ ${ }^{2}$ Department of Epidemiology, Human Genetics and Environmental Sciences, The University of Texas School of Public Health, Houston, \\ Texas, USA \\ ${ }^{3}$ Division of Biostatistics, School of Medicine, Washington University in St. Louis, St. Louis, Missouri, USA \\ Email: andersonfaye7@gmail.com
}

How to cite this paper: Anderson, F., Delclos, G.L. and Rao, D.C. (2016) The Effect of Air Pollutants and Socioeconomic Status on Asthma in Texas. Journal of Geoscience and Environment Protection, 4, 39-52. http://dx.doi.org/10.4236/gep.2016.49004

Received: August 24, 2016

Accepted: September 16, 2016

Published: September 19, 2016

Copyright (c) 2016 by authors and Scientific Research Publishing Inc. This work is licensed under the Creative Commons Attribution International License (CC BY 4.0).

http://creativecommons.org/licenses/by/4.0/

\begin{abstract}
Asthma prevalence in the United States and the world has been increasing, affecting millions including children ( 0 - 17 years old) and causing thousands of deaths every year at a societal cost of over billions of dollars. Further, it has been documented that asthma morbidity responds to socioeconomic variations. This study evaluates the relationship between asthma and five air pollutants along with socioeconomic status in Texas counties from 2005 to 2013. Air pollutants investigated were carbon monoxide (CO), nitrogen dioxide $\left(\mathrm{NO}_{2}\right)$, ozone $\left(\mathrm{O}_{3}\right)$, fine particulate matter (PM2.5), and sulfur dioxide $\left(\mathrm{SO}_{2}\right)$. Exploratory and spatial analyses produced consistent results. Asthma prevalence was positively associated with $\mathrm{PM} 2.5, \mathrm{SO}_{2}$, living near a park, and living in an urban area. Asthma childhood prevalence rates were positively associated with living in a household with a female head and negatively associated with ethnicity: Caucasian, Hispanic, and African American. Adult prevalence rates were positively associated with living in a household with female head, being on food stamps, and PM2.5. Both the overall and adult rates were positively associated with poverty. Asthma hospitalizations in Texas were positively associated with aerosol particles, sulfur dioxide, and low income. Moreover, the majority of air pollution in Texas is formed by stationary sources, which contradicts recent claims that mobile sources are the main emitters in Texas. Our findings are consistent with those from other geographical locations and suggest that additional studies and measures are required to fully explain the associations detected and underlying cause and effect paradigm.
\end{abstract}

\section{Keywords}

Children Asthma, Respiratory, $\mathrm{CO}, \mathrm{NO}_{2}, \mathrm{PM} 2.5$, Ozone, $\mathrm{SO}_{2}$ 


\section{Introduction}

Asthma prevalence in the United States and the world has been increasing, affecting more than 26 million in the US, including 7 million children ( 0 - 17 years old) and is associated with asthma attributed death rate of more than 3600 deaths every year [1]. Asthma is a chronic disease affecting air passages of the lungs. It is the most common childhood disease in developed countries [2]. The most substantial risk factors are environmental allergens and exposure to chemicals and particles which trigger allergic reactions and irritate the airways. The majority of asthma-related mortality occurs in lower income countries [3] [4]. Research on environmental effects on asthma has demonstrated strong associations between asthma presentation and concentrations of criteria air pollutants: carbon monoxide $(\mathrm{CO})$, nitrogen dioxide $\left(\mathrm{NO}_{2}\right)$, ozone $\left(\mathrm{O}_{3}\right)$, fine particulate matter (PM2.5), and sulfur dioxide $\left(\mathrm{SO}_{2}\right)$ [5]-[11]. Asthma symptoms include coughing, wheezing, chest tightness, and shortness of breath. These affect quality of life and work or school productivity. Its societal burden includes these consequences as well as health care burden and mortality.

The economic costs of asthma to society in the United States (US) are estimated to exceed $\$ 60$ billion per year [4]. Population proportion calculation makes Texas' share exceed $\$ 5$ billion per year. Furthermore, because air pollutants levels decrease with increased distance to source, the majority of studies on its health effects have small scale [10], which limits our understanding of the spatial variations of its impact at a regional level. Moreover, studies focusing on the impact of socioeconomic status (SES) on asthma have demonstrated varying degrees of associations with factors like income, college education attainment, and living in urban or rural areas. These associations varied with demographic factors such as age and ethnicity [5] [7] [12] [13]. The effect of SES on asthma morbidity and mortality is attributed to factors such as living conditions, working environment, proximity to air pollutant discharge, and psychosomatic stress [7] [14].

There remain many unanswered questions regarding environmental exposure, SES, and asthma prevalence. Specifically, not all geographical locations have been fully characterized and the datasets have yet to be fully analyzed to present a comprehensive understanding regarding all possible interactions and sequela associated with asthma. This shortcoming hampers our ability for identifying and proposing alternative solutions to this intricate health problem. The objective of this study was to assess the association between asthma and both air pollutants and socioeconomic factors in Texas, from 2005 to 2013. Because of the importance of the effect of air pollutants and SES, these factors needed to be fully characterized for the different settings where local and global factors vary between locations.

\section{Methods}

Asthma hospital discharge rates by county in Texas, for all ages, from 2005 to 2013 were obtained from the Texas Department of State Health Services (DSHS) [15], using International Classification of Diseases Version 9 (ICD-9) codes 490.0 to 493.9. Obser- 
vations for $\mathrm{CO}, \mathrm{NO}_{2}, \mathrm{O}_{3}, \mathrm{PM} 2.5$, and $\mathrm{SO}_{2}$ were downloaded from the website of the United States Environmental Protection Agency (EPA) [16], and interpolated using ordinary kriging in order to calculate the annual mean for each of the five pollutants for each county. Ordinary kriging spatially estimates measurements while minimizing error variance [17]. Socioeconomic status variables were the percentage without college education, percentage of households with female head, percentage living in poverty (all ages) (poverty index), percentage of population with Native origins, percentage of population of Asian origins, percentage of population who is African American, percentage of population of Hispanic origins, percentage of Caucasian population, percentage of population living within half a mile of a park, percentage of households with severe housing problems, and percentage of population living in urban-rural area. These were collected from the U.S. Census website [18] for the same years.

To investigate temporal effects, Fisher's F-test was used to test the null hypothesis of non-changing variances between years. Repeated measures t-test was used to test the null hypothesis of non-changing means between the years. Pearson pair-wise correlations were calculated to test for collinearity between the independent variables.

For multivariate multiple linear regression analysis, the following regression equation was used: [Overall Rate, Children Rate, Adult Rate] $=\beta 0+\beta \mathrm{X}+\varepsilon$, where $\beta 0$ is the intercept, $\beta$ is the matrix of regression coefficients, and $\mathrm{X}$ is the matrix of independent variables [19]. Variables included in the regression model: annual average concentration of $\mathrm{CO}, \mathrm{NO}_{2}, \mathrm{O}_{3}, \mathrm{PM} 2.5$, and $\mathrm{SO}_{2}$, college education attainment, food stamp users, poverty index, ethnicity, living near a park, percentage of households with severe housing problems, and living in urban/rural area (Table 1).

Moran I, which is an indicator of spatial dependence, was calculated as a measure of spatial differences between the variables. Kriging was used to interpolate annual average estimates of PM2.5 for every county. The multivariate spatial regression lag model employed was: [Overall Rate, Children Rate, Adult Rate] $=\mathrm{W} \gamma+\beta \mathrm{sX}+$ spatial residuals, where $\mathrm{W} \gamma$ is spatially lagged dependent variable for the weights matrix $\mathrm{W}, \beta \mathrm{s}$ is the regression coefficients, and $\mathrm{X}$ is the matrix of predictors as in the linear regression. The Weights matrix stores all the pairwise spatial relationships in the dataset [17]. Linear and spatial analyses were conducted at the significance level of 0.05 using $\mathrm{R}$ version 3.1.1 [20]. ArcMap 10.3.1 [21] was used for mapping.

\section{Results}

\subsection{Descriptive Analyses}

Figure 1 presents the total number of asthma hospitalizations in Texas from 2005 to 2013. Fisher's F-test p-values were greater than the significance level of 0.05 . Hence, we could not reject the null hypothesis of equal variances. Repeated measures t-test p-values were also greater than the significance level of 0.05 . Thus, the dataset did not reveal temporal effects which allowed us to use the data for the year 2012 as a representative of all nine years' data. Figure 2(a) presents asthma hospitalizations for the year 2012, where all asthma hospitalizations had a county assignment. Because of county population 
Table 1. List of variables collected and analyzed statistics for this study and their resources.

\begin{tabular}{|c|c|}
\hline Variable & Resource \\
\hline Asthma hospitalization All Ages All Race All Gender & DSHS \\
\hline Asthma Rate per 10,000 All Ages All Race All Gender & DSHS \\
\hline Asthma Adult Rate per 10,000 All Ages All Race All Gender & DSHS \\
\hline Asthma Children Rate per 10,000 All Ages All Race All Gender & DSHS \\
\hline Annual Average Ambient Concentrations of $\mathrm{CO}(\mathrm{ppm})$ & EPA \\
\hline Annual Average Ambient Concentrations of $\mathrm{NO}_{2}(\mathrm{ppb})$ & EPA \\
\hline Annual Average Ambient Concentrations of $\mathrm{O}_{3}(\mathrm{ppm})$ & EPA \\
\hline Annual Average Ambient Concentrations of PM2.5 $\left(\mu \mathrm{g} / \mathrm{m}^{3}\right)$ & EPA \\
\hline Annual Average Ambient Concentrations of $\mathrm{SO}_{2}(\mathrm{ppb})$ & EPA \\
\hline Percentage without $4+$ Years College (\%) & US Census \\
\hline Families with Female Head of Household (\%) & US Census \\
\hline Percentage Living in Poverty All Ages (\%) & US Census \\
\hline Percentage of population with native origins (\%) & US Census \\
\hline Percentage of population of Asian origins (\%) & US Census \\
\hline Percentage of population that is African American (\%) & US Census \\
\hline Percentage of population of Hispanic origins (\%) & US Census \\
\hline Percentage of Caucasian population (\%) & US Census \\
\hline Percentage of Population Living Within Half a Mile of a Park 2010 & US Census \\
\hline Percentage of Households Living with Severe Housing Problems (\%) & US Census \\
\hline Percentage of population living in urban-rural area (\%) & US Census \\
\hline
\end{tabular}

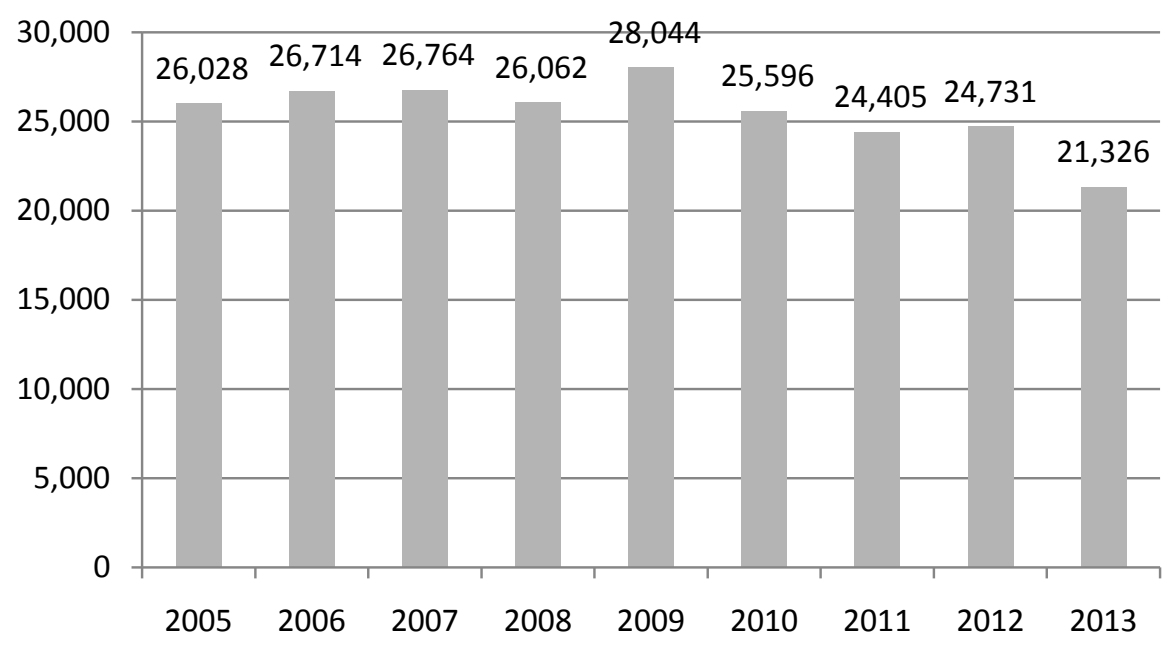

Figure 1. Texas asthma hospitalizations from 2005 to 2013.

variances, asthma rates presented in Figure 2(b) are the population-adjusted hospitalizations. Childhood asthma accounted for $88 \%$ of the Texas reported overall hospitalization admissions. The standard deviation was high, indicating variability across Texas counties (Table 2). Table 3 presents asthma hospitalizations and rates for each ur- 


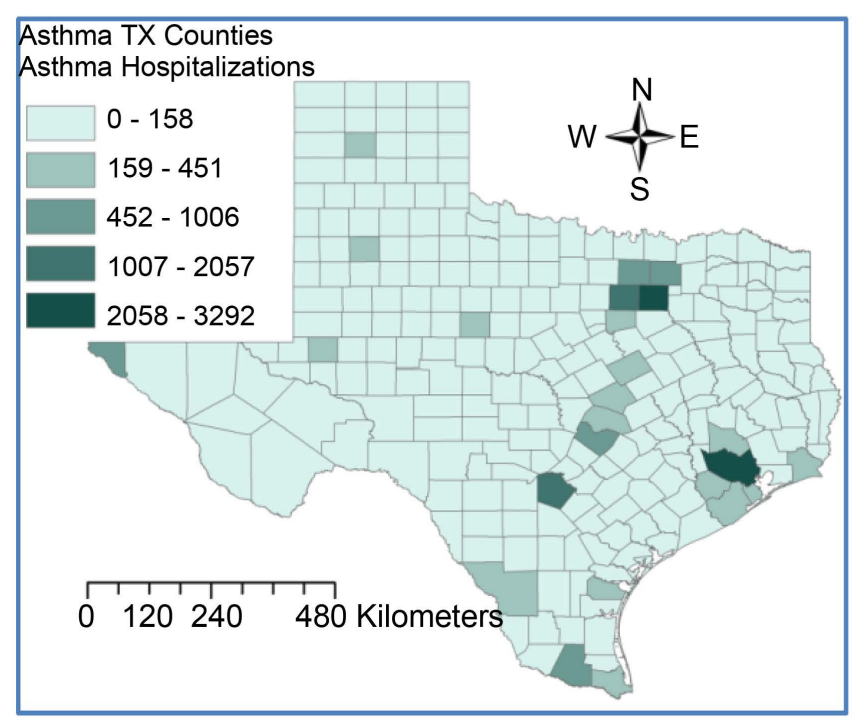

(a)

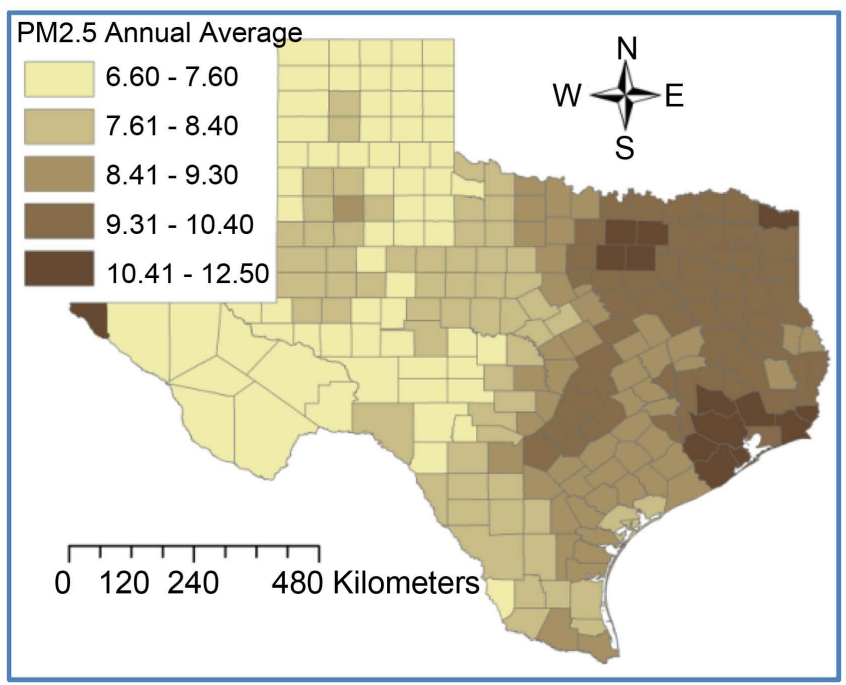

(c)

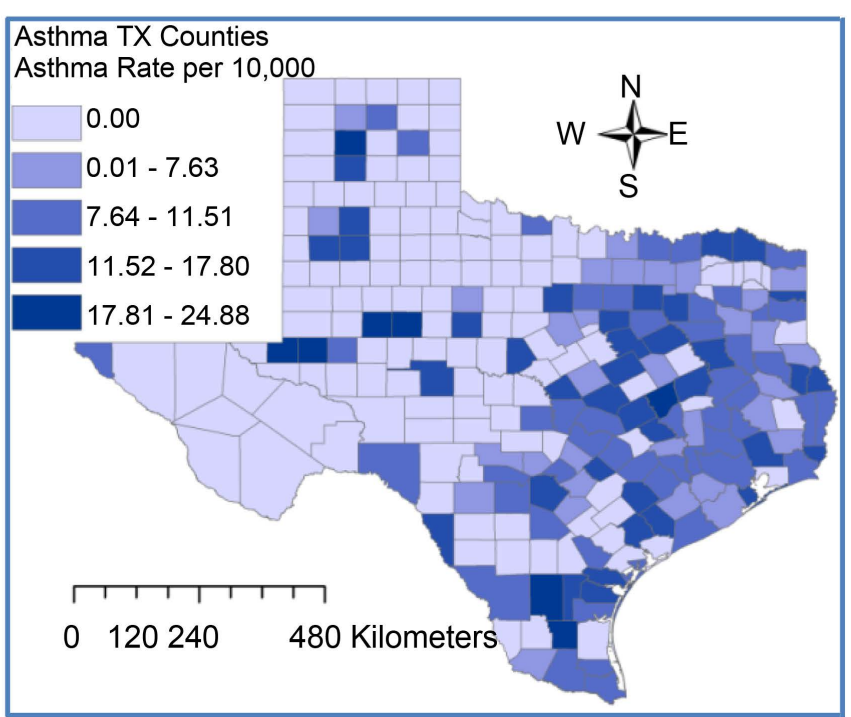

(b)

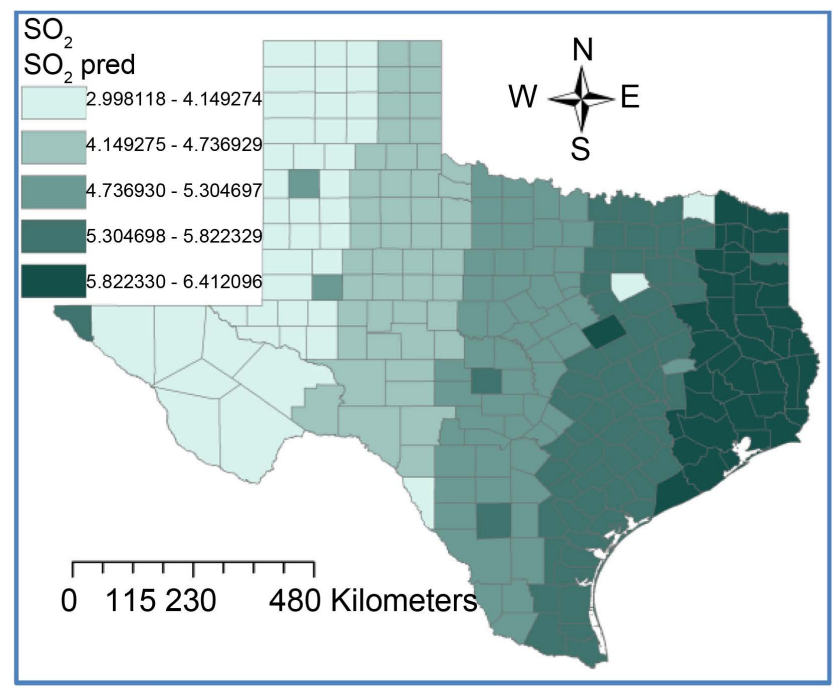

(d)

Figure 2. Asthma hospitalizations and annual averages of PM2.5 and $\mathrm{SO}_{2}$ for Texas counties for 2012.

ban-rural area classification. The greatest number of asthma hospitalizations was localized to large central metro areas and the numbers decreased with decreased urbanization. Table 4 presents the percentage of the population for the main five ethnicities accounted for. On average, $58 \%$ of the study population was Caucasian, 33\% Hispanic, and 6\% African American. Socioeconomic factors are summarized in Table 5. The percentage of individuals with 4 years of college was high at $82 \%$ (7.22), the percentage of households reporting a female head of household averaged 17\% (5.31), and those classified as living at or below the poverty line averaged $18 \%$ (5.65).

Non-negligible $(\rho>0.1)$ pair-wise correlations are presented in Table 6. Asthma hospitalizations were negatively associated with less than a college education $(\rho=-0.37)$, positively correlated with households with a female head $(\rho=0.23)$, modestly correlated with Asian ethnicity $(\rho=0.42)$, living near a park $(\rho=0.40)$ and with PM2.5 air con- 
Table 2. Summary statistics for asthma hospitalization, rate per 10,000, children rate, and adult rate.

\begin{tabular}{ccccc}
\hline & Asthma Hospitalization & Asthma Rate & Children Rate & Adult Rate \\
\hline Mean & 95.02 & 5.34 & 5.26 & 4.21 \\
Median & 12.50 & 3.66 & 0.00 & 0.00 \\
Mode & 0.00 & 0.00 & 0.00 & 0.00 \\
Std. Dev. & 338.28 & 6.18 & 9.55 & 5.40 \\
Min & 0.00 & 0.00 & 0.00 & 0.00 \\
Max & 3292.00 & 24.88 & 58.80 & 27.00 \\
\hline
\end{tabular}

Table 3. Summary statistics for each urban-rural classification for asthma hospitalization, rate per 10,000, children rate, and adult rate, in Texas for 2012.

\begin{tabular}{ccccc}
\hline Urban-Rural & Asthma Hospitalizations & Asthma Rate & Children Rate & Adult Rate \\
\hline Large Central Metro & 11,448 & 9.37 & 14.95 & 7.47 \\
Large Fringe Metro & 3810 & 7.58 & 8.51 & 6.61 \\
Medium/Small Metro & 6685 & 8.37 & 11.37 & 6.22 \\
Non-metro & 2193 & 4.00 & 2.71 & 3.14 \\
\hline
\end{tabular}

Table 4. Demographic statistics for the main five ethnic groups in Texas for 2012 [18].

\begin{tabular}{cccccc}
\hline & Native & Asian & Black & Hispanic & Caucasian \\
\hline Mean & 0.30 & 0.85 & 6.18 & 32.89 & 58.43 \\
Median & 0.20 & 0.40 & 3.85 & 24.55 & 61.90 \\
Mode & 0.00 & 0.00 & 0.00 & 16.30 & 87.20 \\
Std. Dev. & 0.58 & 1.71 & 6.71 & 23.09 & 21.17 \\
Min & 0.00 & 0.00 & 0.00 & 2.20 & 1.20 \\
Max & 8.00 & 17.30 & 33.30 & 98.40 & 96.50 \\
\hline
\end{tabular}

Table 5. Descriptive statistics for the socioeconomic factors for Texas in 2012 [18].

\begin{tabular}{ccccccc}
\hline & $\begin{array}{c}\text { College Education } \\
\text { Attainment }\end{array}$ & Female Head & Food Stamp & Poverty & $\begin{array}{c}\text { Near } \\
\text { Park }\end{array}$ & $\begin{array}{c}\text { Housing } \\
\text { Problems }\end{array}$ \\
\hline Mean & 82.26 & 17.08 & 15.58 & 18.15 & 18.48 & 14.13 \\
Median & 83.90 & 16.90 & 14.75 & 17.90 & 13.00 & 13.80 \\
Mode & 84.30 & 16.90 & 13.60 & 18.70 & 0.00 & 10.70 \\
Std. Dev. & 7.22 & 5.31 & 6.53 & 5.65 & 17.81 & 4.30 \\
Min & 50.60 & 3.40 & 2.50 & 6.60 & 0.00 & 0.00 \\
Max & 94.80 & 32.80 & 43.60 & 43.10 & 74.00 & 32.20 \\
\hline
\end{tabular}

centration data $(\rho=0.42)$. $\mathrm{SO}_{2}$ was strongly associated with $\mathrm{PM} 2.5(\rho=0.77)$ and being African American $(\rho=0.60)$. It was positively associated with asthma $(\rho=0.33)$ and negatively associated with being Hispanic $(\rho=-0.39)$ and living near a park $(\rho=$ $-0.38)$. 
Monitored overall PM2.5 concentrations were below the National Ambient Air Quality Standards (NAAQS) of $12.0 \mu \mathrm{g} / \mathrm{m}^{3}$ while the percentage of population reporting living near a park was less than $19 \%$ (17.81). Table 7 presents descriptive statistics for $\mathrm{CO}, \mathrm{NO}_{2}, \mathrm{O}_{3}, \mathrm{PM} 2.5$, and $\mathrm{SO}_{2}$ for 2012. Their averages were all under NAAQS standard levels, and their standard deviations were not high. PM2.5 and $\mathrm{SO}_{2}$ county annual averages for 2012 are presented in Figure 2(c) and Figure 2(d) respectively. Higher PM2.5 concentrations prevailed in and around large urban Texas cities (Dallas, Houston, Austin, El Paso), whereas higher $\mathrm{SO}_{2}$ levels were increasingly to the east of the state, especially Newton, Orange, Sabine, and Jefferson counties (Figure 3).

Table 6. Non-negligible pair-wise correlation coefficients.

\begin{tabular}{|c|c|c|c|c|c|c|c|c|c|c|c|}
\hline & Asthma & $\begin{array}{c}\text { Without } \\
\text { College } \\
\text { Education }\end{array}$ & $\begin{array}{c}\text { Female } \\
\text { Head }\end{array}$ & $\begin{array}{l}\text { Food } \\
\text { Stamp }\end{array}$ & Poverty & Native & Asian & Black & Hispanic & Park & $P M 2.5$ \\
\hline Education & -0.37 & 1.00 & & & & & & & & & \\
\hline Female Head & 0.23 & 0.29 & 1.00 & & & & & & & & \\
\hline $\begin{array}{l}\text { Food } \\
\text { Stamp }\end{array}$ & -0.02 & 0.46 & 0.71 & 1.00 & & & & & & & \\
\hline Poverty & -0.04 & 0.46 & 0.64 & 0.82 & 1.00 & & & & & & \\
\hline Native & -0.13 & 0.04 & -0.04 & -0.10 & -0.12 & 1.00 & & & & & \\
\hline Asian & 0.42 & -0.55 & 0.08 & -0.15 & -0.19 & -0.04 & 1.00 & & & & \\
\hline Black & 0.15 & 0.03 & 0.33 & 0.08 & 0.14 & -0.07 & 0.28 & 1.00 & & & \\
\hline Hispanic & 0.16 & 0.28 & 0.41 & 0.55 & 0.45 & -0.11 & -0.07 & -0.39 & 1.00 & & \\
\hline Park & 0.40 & -0.19 & 0.06 & -0.06 & -0.11 & -0.05 & 0.20 & -0.10 & 0.24 & 1.00 & \\
\hline PM2.5 & 0.42 & -0.23 & 0.22 & 0.02 & -0.07 & -0.04 & 0.43 & 0.61 & -0.37 & -0.13 & 1.00 \\
\hline $\mathrm{SO}_{2}$ & 0.33 & 0.00 & 0.21 & 0.13 & 0.09 & -0.14 & 0.17 & 0.60 & -0.39 & -0.38 & 0.77 \\
\hline $\begin{array}{l}\text { Housing } \\
\text { Problems }\end{array}$ & 0.31 & -0.07 & 0.54 & 0.53 & 0.47 & -0.22 & 0.21 & 0.15 & 0.37 & 0.10 & 0.34 \\
\hline
\end{tabular}

Table 7. Descriptive statistics for the five air pollutants, Texas, 2012.

\begin{tabular}{cccccc}
\hline & $\mathrm{CO}(\mathrm{ppm})$ & $\mathrm{NO}_{2}(\mathrm{ppb})$ & $\mathrm{O}_{3}(\mathrm{ppm})$ & $\mathrm{PM} 2.5\left(\mu \mathrm{g} / \mathrm{m}^{3}\right)$ & $\mathrm{SO}_{2}(\mathrm{ppb})$ \\
\hline Mean & 0.93 & 26.08 & 0.02 & 8.61 & 5.04 \\
Standard Deviation & 0.23 & 4.86 & 0.00 & 1.17 & 0.76 \\
Minimum & 0.52 & 15.99 & 0.02 & 6.60 & 3.00 \\
Maximum & 1.52 & 39.62 & 0.03 & 12.50 & 6.41 \\
\hline
\end{tabular}

\subsection{Spatial Regression Analysis}

The codispersion coefficient is interpreted as the linear correlation coefficient between spatial increments of the variables studied. Figure 4 demonstrates that codipersion coefficient decreases with distance between the counties and that the interdependence between the variables increases with decreasing distance. In addition, Moran's I value was less than or equal to 0.11 , which is significant, indicating a strong spatial autocorrelation with the outputted residuals. Therefore, multivariate multiple linear and spatial 


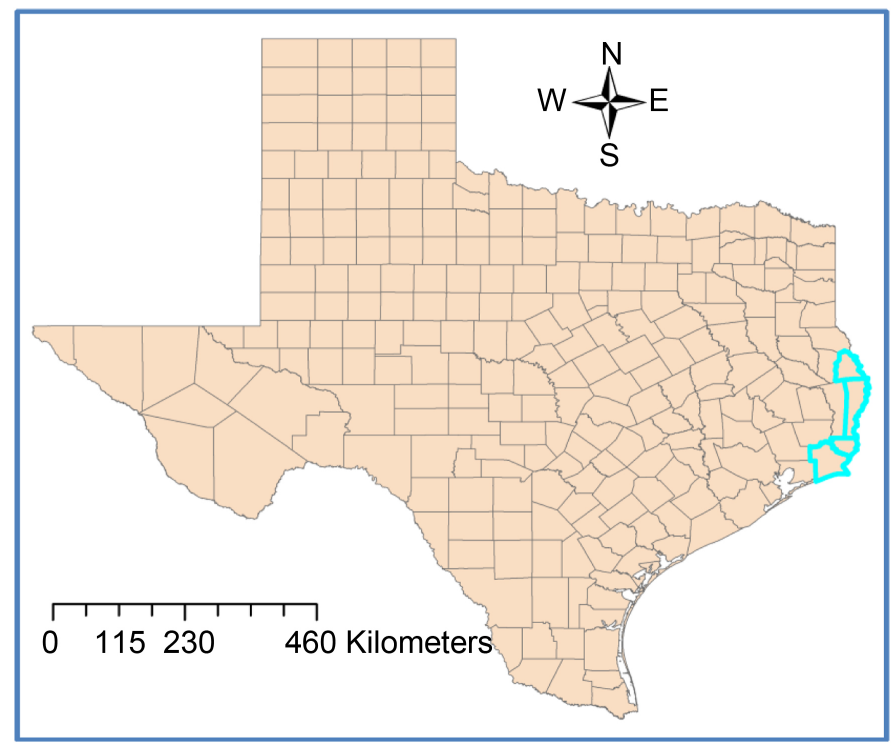

Figure 3. Texas counties with highest annual $\mathrm{SO}_{2}$ levels in 2012: Newton, Orange, Sabine and Jefferson counties.

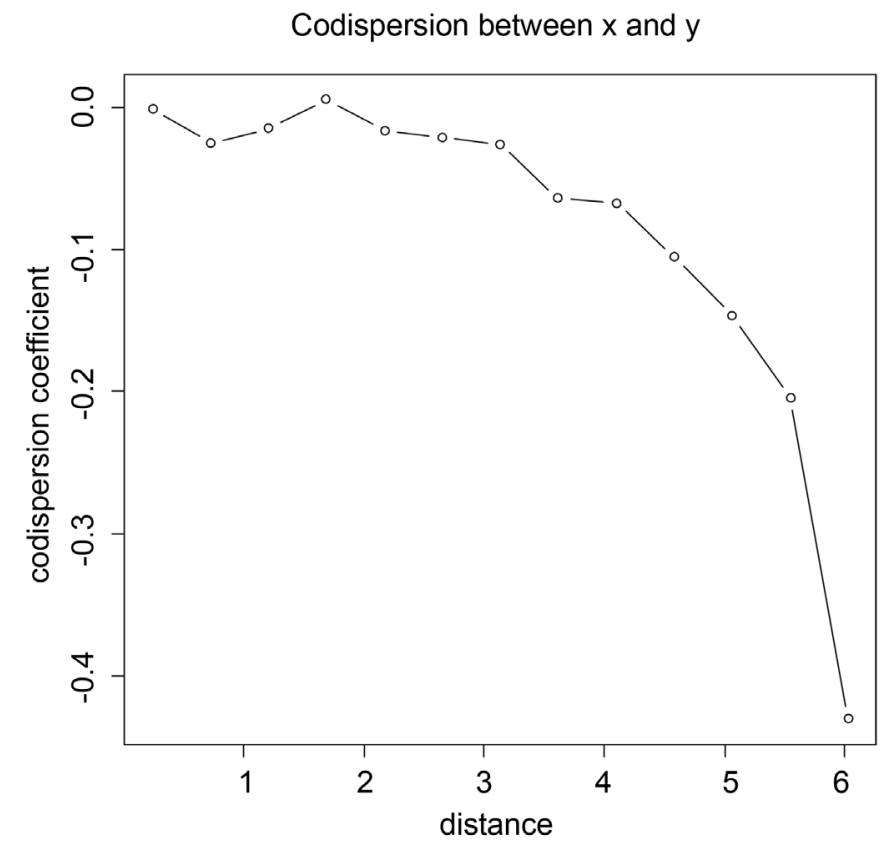

Figure 4. Codispersion coefficients between county centroid longitudes (x) and latitudes (y).

regressions were used to investigate the most significant independent variables. Table 8 presents the statistically significant predictors for each dependent variable entered into the regression model. Both, linear and spatial regressions outputs were closely aligned indicating alignment between linear and spatial models. For asthma hospitalizations, being near a park, PM2.5, and living in an urban area were statistically significant. The regression coefficient for PM2.5 was as high as 60.10, which means that for each 1 
Table 8. Statistically significant regression coefficients (p-value $<0.05$ ).

\begin{tabular}{|c|c|c|c|c|c|c|c|c|c|c|}
\hline $\begin{array}{c}\text { Dependent } \\
\text { Variable }\end{array}$ & $\begin{array}{c}\text { Female } \\
\text { Head }\end{array}$ & $\begin{array}{l}\text { Food } \\
\text { Stamp }\end{array}$ & Poverty & Black & Hispanic & Caucasian & Park & PM2.5 & $\mathrm{SO}_{2}$ & Urban \\
\hline Hospitalizations & & & & & & & 3.49 & 60.1 & 45.3 & 151.24 \\
\hline Overall Rate & 0.29 & 0.27 & 0.29 & & & & & & & 1.09 \\
\hline Children Rate & 0.62 & & & -1.67 & -1.63 & -1.63 & 0.07 & & & \\
\hline Adult Rate & 0.22 & 0.26 & 0.25 & & & & & 1.21 & 1.1 & \\
\hline
\end{tabular}

$\mu \mathrm{g} / \mathrm{m}^{3}$ increase in PM2.5 asthma rate increases by an average of 60.10 .

Living in rural areas demonstrated a strong negative association with asthma hospitalizations with a regression coefficient of $-151.24, \mathrm{p}<0.05$. For the regression on adult asthma rates, living in a household with female head and benefiting from food stamps were positively associated with regression coefficients of 0.29 and 0.27 respectively, which meant that for each 1 per cent increase in the population living in a household with female head, adult asthma rate increased by an average of 0.29 , and for each 1 per cent increase in food stamps usage, adult asthma rate increased by an average of 0.27 . Poverty and urban living were positively associated with regression coefficients of 0.29 and 1.09, respectively. This means that for each 1 per cent increase in the population living in poverty, the adult asthma rate increased by an average of 0.29 and for each 1 per cent increase in population living in an urban area, the adult asthma rate increased by an average of 1.09 (Table 8).

For the regression on children asthma rate, living in a household with female head and living near a park were positively associated with regression coefficients of 0.62 and 0.07 respectively. Whereas being African American, Hispanic, or Caucasian were negatively associated with regression coefficients of $-1.67,-1.63$, and -1.63 respectively. For the regression on the combined asthma rate (both adults and children), living in a household with female head, benefiting from food stamps, and PM2.5 were positively associated with regression coefficients of $0.22,0.26$, and 1.21 respectively. Whereas asthma rate increased with decreased poverty (regression coefficient of 0.25 , p-value < 0.05). Regressing on childhood asthma rate alone indicated that living in a household with a female head of household increased asthma hospitalization rate by 0.62 , whereas, a female head of household for adult admissions yields a regression coefficient of 0.22 , p-value $<0.05$. Therefore, PM2.5 accounted for a significant number of hospitalizations especially adult's rate, but not children's rate. $\mathrm{SO}_{2}$ was significantly associated with adult asthma rate (regression coefficient $1.1, \mathrm{p}<0.05$ ). Table 9 summarizes the statistically significant associations in the multivariate multiple linear and spatial regressions.

\section{Discussion}

From the analysis presented, we found consistent positive associations between asthma prevalence and ambient concentrations of PM2.5 and $\mathrm{SO}_{2}$. The associations were consistent with other studies in the United States [7] [10] [22]-[24] and other locations [7] [25] [26] regardless of the linear or spatial statistical method used. One microgram $/ \mathrm{m}^{3}$ 
Table 9. Multivariate multiple linear and spatial regressions results.

\begin{tabular}{cc}
\hline Dependent Variable & Significant Predictors \\
\hline Asthma Overall Rate & Households with female heads, food stamps, poverty. \\
Asthma Children Rate & Households with female heads, African American, \\
Hispanic, Caucasian, and near park. & Households with female heads, on food stamps, poverty, PM2.5, and $\mathrm{SO}_{2}$. \\
\hline
\end{tabular}

increase in PM2.5 was associated with 60 more asthma hospitalizations, whereas one ppb increase in $\mathrm{SO}_{2}$ was associated with 45 more hospitalizations on average. Living in a household with female head was associated with 1.50 increase in asthma overall rate, 3.26 increase in children rate, and 0.92 increase in adult rate.

Comparing Figure 2(b) and Figure 2(c), it is apparent that the average trends of asthma rate and $\mathrm{SO}_{2}$ annual level are in agreement. The high association between fine particulate matter and sulfer dioxide suggests that PM2.5 was created by secondary formation from precursor emissions of $\mathrm{SO}_{2}$, especially in the spring and summer seasons. According to EPA (2016), Houston and Fort Worth/Dallas areas have $\mathrm{SO}_{2}$ levels that do not meet the mimimum trends completeness criteria [27]. This is consistent with the high asthma hospitalizations seen in Figure 2(a). This also indicates that the majority of PM2.5 that is associated with asthma hospitalizations is generated by stationary sources like the refineries and plants in Houston and Fort Worth/Dallas cities as well as the four eastern counties with highest $\mathrm{SO}_{2}$ concentrations (Figure 3). This is a significant contradiction to policy makers claims that stationary emitters in Texas are under control [28].

Being on food stamps and poverty were associated with increased in the overall and adult rated. These results have been consistent with previous research in other locations [7] [25]. Poverty was strongly associated with being on food stamps $(\rho=0.82)$, using food stamps and having a poverty "status" are mutually exclusive [29], and both were statistically significant to asthma adult and overall rates. This is an indicator of confounding between the two (poverty and food status) and that only one of them is a sound representative of household income.

Although living in a household with a female head was significantly associated with all asthma rates (overall, adults, children), it had a larger impact on children asthma rate (regression coefficient 0.62 versus 0.22 ). This is consistent with similar findings in other studies [30]. Living in a household with a female head had a correlation coefficient of 0.64 with poverty. This supports the literature that associates asthma prevalence with low income especially in urban areas where indoor pollutants are one of the most important causes of asthma exacerbations [31] [32].

As for ethnicity, previous studies demonstrated that Mexican-Americans have lower prevalence of asthma than Caucasians or African Americans [33]-[35], and African Americans have higher prevalence [1] [7] [35]-[37], this study showed that there was not a specific race group that stood out among others. 
In this study, the three main categories were statistically significant to children's asthma. Percentages of African American, Hispanic and Caucasians were associated with about 3.5 average decrease in children's asthma rate for hospitalizations. The negatively associated regression coefficients for the three ethnicities were very similar in value, which does not provide knowledge on how ethnicity interactions affect asthma prevalence in Texas, which calls for further investigation.

In summary, our results demonstrated significant positive associations between asthma prevalence in Texas and air pollutants and socioeconomic factors. We further demonstrated a statistically significant association between asthma prevalence and living in a household with female head. Moreover, children's asthma was positively associated with the main three ethnicities (Caucasian, Hispanic, and African American), as well as, living near a park. Lastly, overall asthma rate was positively correlated with living in an urban area.

\section{Conclusion}

This study investigates the association of air pollutants and socioeconomic factors with asthma in Texas. The analyzed dataset was formed from three different sources: DSHS, EPA, and US Census. Statistical analyses point to three associations with asthma: $\mathrm{PM} 2.5, \mathrm{SO}_{2}$, and income. Despite the limitations of the data, this is the first study for a large location like the state of Texas which covers spatial variations. These affect the levels of air pollutants due to differences in meteorological interactions as well as variations in the distribution of stationary sources. Future studies are recommended to investigate these associations in a smaller scale, gene-by-environment interactions, lifestyle factors, and comparisons to other states. Finally, the findings of this study point to the need for more strict regulations on $\mathrm{PM} 2.5$ and $\mathrm{SO}_{2}$ sources even under attainment conditions.

\section{Strengths and Limitations}

Although the annual averages do not reflect within year temporal and/or spatial variations in the association, the analyses performed captured some of the important relationships between asthma prevalence and both air pollution and SES. Although the data did not allow for investigation of intra-county variations, it allows for an overall understanding of the relationships between asthma and particulate pollution as well as SES, which are of significant impact for policy makers and researchers to quantify the burden of asthma.

The downloaded asthma dataset did not include emergency visits or mortality therefore underestimating the disease burden of asthma in Texas. Additionally, important confounders like age, gender, and smoking status were not accounted for. The data used is not a complete source of asthma hospitalizations in Texas because they come from volunteering hospitals and not all of hospitals. This underestimates the rates. Lastly, asthma hospitalizations may also be underrepresented based on hospital reporting characteristics, data extraction, and coding processes used in each hospital. 


\section{References}

[1] CDC (2015) Asthma. http://www.cdc.gov/nchs/fastats/asthma.htm

[2] Dimitrova, R., et al. (2012) Relationship between Particulate Matter and Childhood Asthma-Basis of a Future Warning System for Central Phoenix. Atmospheric Chemistry \& Physics, 12, 2479-2490. http://dx.doi.org/10.5194/acp-12-2479-2012

[3] WHO (2013) Asthma. http://www.who.int/mediacentre/factsheets/fs307/en/

[4] Barnett, S.B.L. and Nurmagambetov, T.A. (2011) Costs of Asthma in the United States: 2002-2007. The Journal of Allergy and Clinical Immunology, 127, 145-152. http://dx.doi.org/10.1016/j.jaci.2010.10.020

[5] Anderson, F., et al. (2015) Age, Race and Gender Spatiotemporal Disparities of COPD Emergency Room Visits in Houston, Texas. Occupational Diseases and Environmental Medicine, 3, 1-9. http://dx.doi.org/10.4236/odem.2015.31001

[6] Bates, D.V. and Sizto, R. (1987) Air pollution and Hospital Admissions in Southern Ontario: The Acid Summer Haze Effect. Environmental Research, 43, 317-331. http://dx.doi.org/10.1016/S0013-9351(87)80032-4

[7] Burra, T.A., et al. (2009) Social Disadvantage, Air Pollution, and Asthma Physician Visits in Toronto, Canada. Environmental Research, 109, 567-574.

http://dx.doi.org/10.1016/j.envres.2009.03.004

[8] Price, G. (2007) Effects of Weather, Air Quality and Geographical Location on Asthma and COPD Exacerbations in the Localities of Worcester and Dudley. Ph.D. Thesis, Coventry University, Coventry.

[9] Brunekreef, B. and Holgate, S.T. (2002) Air Pollution and Health. The Lancet, 360, 12331242. http://dx.doi.org/10.1016/S0140-6736(02)11274-8

[10] Smargiassi, A., et al. (2009) Risk of Asthmatic Episodes in Children Exposed to Sulfur Dioxide Stack Emissions from a Refinery Point Source in Montreal, Canada. Environmental Health Perspectives, 117, 653-659. http://dx.doi.org/10.1289/ehp.0800010

[11] CDC (1999) ToxFAQsTM for Sulfur Dioxide. http://www.atsdr.cdc.gov/toxfaqs/tf.asp?id=252\&tid=46

[12] Gold, D.R. and Wright, R. (2005) Population Disparities in Asthma. Annual Review of Public Health, 26, 89-113. http://dx.doi.org/10.1146/annurev.publhealth.26.021304.144528

[13] Anderson, F. (2016) Application of Multivariate Geostatistics in Environmental Epidemiology: Case Study from Houston, Texas. Journal of Geoscience and Environmental Protection, 4, 110-115. http://dx.doi.org/10.4236/gep.2016.44014

[14] O’Neill, M.S., et al. (2003) Workshop on Air Pollution and Socioeconomic Conditions. Health, Wealth, and Air Pollution: Advancing Theory and Methods. Environmental Health Perspectives, 111, 1861-1870. http://dx.doi.org/10.1289/ehp.6334

[15] DSHS (2005-2013) TACP Data. http://www.dshs.state.tx.us/Layouts/ContentPage.aspx?PageID=34548\&id=34582\&terms=a sthma

[16] EPA (2016) AirData. http://aqsdr1.epa.gov/aqsweb/aqstmp/airdata/download files.html\#Annual

[17] Fischer, M.M. and Getis, A. (2009) Handbook of Applied Spatial Analysis: Software Tools, Methods and Applications. Springer, Berlin.

[18] Census (2011) American Fact Finder. http://factfinder.census.gov/faces/nav/jsf/pages/index.xhtml 
[19] Rencher, A.C. and Christensen, W.F. (2012) Methods of Multivariate Analysis. Wiley, Hoboken, 800. http://dx.doi.org/10.1002/9781118391686

[20] Core, R. (2014) R: A Language and Environment for Statistical Computing.

[21] ESRI (2015) ArcMap 10.3.1. ESRI, Redlands.

[22] Sinclair, A.H. and Tolsma, D. (2004) Associations and Lags between Air Pollution and Acute Respiratory Visits in an Ambulatory Care Setting: 25-Month Results from the Aerosol Research and Inhalation Epidemiological Study. Journal of the Air \& Waste Management Association, 54, 1212-1218. http://dx.doi.org/10.1080/10473289.2004.10470979

[23] Atkinson, R.W., et al. (1998) Short-Term Associations between Emergency Hospital Admissions for Respiratory and Cardiovascular Disease and Outdoor Air Pollution in London. Archives of Environmental Health, 54, 398-411. http://dx.doi.org/10.1080/00039899909603371

[24] Orazzo, F., et al. (2009) Air Pollution, Aeroallergens, and Emergency Room Visits for Acute Respiratory Diseases and Gastroenteric Disorders among Young Children in Six Italian Cities. National Institute of Environmental Health Sciences, 1780.

[25] Hajat, A., et al. (2013) Air Pollution and Individual and Neighborhood Socioeconomic Status: Evidence from the Multi-Ethnic Study of Atherosclerosis (MESA). Environmental Health Perspectives, 121, 1325-1333.

[26] Hajat, A., Haines, A., Goubet, S.A., Atkinson, R.W. and Anderson, H.R. (1999) Association of Air Pollution with Daily GP Consultations for Asthma and Other Respiratory Conditions in London. Thorax, 54, 597-605. http://dx.doi.org/10.1136/thx.54.7.597

[27] EPA (2016) Sulfur Dioxide.

[28] Hopkins, J.S. (2015) In Texas, Environmental Officials Align with Polluters. National Geographic.

[29] Census (2015) How the Census Bureau Measures Poverty. https://www.census.gov/hhes/www/poverty/about/overview/measure.html

[30] Harik-Khan, R.I., Muller, D.C. and Wise, R.A. (2004) Serum Vitamin Levels and the Risk of Asthma in Children. American Journal of Epidemiology, 159, 351-357. http://dx.doi.org/10.1093/aje/kwh053

[31] Krieger, J.W., Song, L., Takaro, T.K. and Stout, J. (2000) Asthma and the Home Environment of Low-Income Urban Children: Preliminary Findings from the Seattle-King County Healthy Homes Project. Journal of Urban Health, 77, 50-67. http://dx.doi.org/10.1007/BF02350962

[32] Anderson, F. and Al-Thani, N. (2016) Female Head, Food Stamps, Ethnicity and Air Pollution: Confounders or Causes of Heart Disease in Texas. Open Journal of Epidemiology, 6, 146-153. http://dx.doi.org/10.4236/ojepi.2016.62015

[33] Flores, G., et al. (2002) The Health of Latino Children: Urgent Priorities, Unanswered Questions, and a Research Agenda. JAMA, 288, 82-90.

http://dx.doi.org/10.1001/jama.288.1.82

[34] Hunninghake, G.M., Weiss, S.T. and Celedón, J.C. (2006) Asthma in Hispanics. American Journal of Respiratory and Critical Care Medicine, 173, 143-163. http://dx.doi.org/10.1164/rccm.200508-1232SO

[35] Forno, E. and Celedón, J.C. (2009) Asthma and Ethnic Minorities: Socioeconomic Status and Beyond. Current Opinion in Allergy and Clinical Immunology, 9, 154-160. http://dx.doi.org/10.1097/ACI.0b013e3283292207 
[36] Barnes, K.C., et al. (2007) African Americans with Asthma. Proceedings of the American Thoracic Society, 4, 58-68. http://dx.doi.org/10.1513/pats.200607-146JG

[37] Control CFD and Prevention (2016) CDC Asthma, BRFSS 2006-Child Asthma Data Technical Information. http://www.cdc.gov/BRFSS/

Submit or recommend next manuscript to SCIRP and we will provide best service for you:

Accepting pre-submission inquiries through Email, Facebook, LinkedIn, Twitter, etc. A wide selection of journals (inclusive of 9 subjects, more than 200 journals)

Providing 24-hour high-quality service

User-friendly online submission system

Fair and swift peer-review system

Efficient typesetting and proofreading procedure

Display of the result of downloads and visits, as well as the number of cited articles

Maximum dissemination of your research work

Submit your manuscript at: http://papersubmission.scirp.org/

Or contact gep@scirp.org 